\title{
To Design a Human Pbpk Model to Evaluate Cadmium Exposure Through Shellfish Consumption in Taiwan
}

Hao-Hsiang Ku

National Taiwan Ocean University https://orcid.org/0000-0003-1537-6724

Pham Thi Tien

National Taiwan Ocean University

Min-Pei Ling ( $\square$ mpling@email.ntou.edu.tw)

National Taiwan Ocean University

\section{Research Article}

Keywords: Risk assessment, Physiologically based pharmacokinetics model, Shellfish, Cadmium, Heavy metal

Posted Date: April 27th, 2021

DOl: https://doi.org/10.21203/rs.3.rs-453395/v1

License: (c) (i) This work is licensed under a Creative Commons Attribution 4.0 International License. Read Full License 
To Design a Human PBPK Model to Evaluate Cadmium Exposure Through Shellfish Consumption in Taiwan

\author{
Hao-Hsiang $\mathrm{Ku}^{12}$, Pham Thi Tien ${ }^{1}$, Min-Pei Ling ${ }^{12^{*}}$ \\ ${ }^{1}$ Institute of Food Safety and Risk Management, National Taiwan Ocean University, \\ ${ }^{2}$ Department of Food Science, National Taiwan Ocean University, \\ No 2 Pei-Ning Road, Zhongzheng Dist., Keelung City 202301, Taiwan, R.O.C \\ Email: mpling@email.ntou.edu.tw
}

\begin{abstract}
This study uses a physiology-based pharmacokinetic model to predict Cadmium (Cd) concentrations in urine and blood through shellfish consumers. The main purpose focus on assessment of human health risk to $\mathrm{Cd}$ through exposure via shellfish in Taiwan. A Hill-based dose-response model is utilized to estimate renal dysfunction and peripheral arterial disease risks in humans after long-term exposure. Sensitivity analyses and Monte Carlo simulations are implemented to support the risk assessment of cadmium in humans. Results indicate that glomerular and tubular damage (GTD) is different between group ages and genders ranged from 17.8067\% - 17.8072\%, respectively. Results show that the peripheral arterial disease prevalence (PADP) ranges from $3.2505 \%-4.5968 \%$ in male and ranges from $4.7168 \%-7.0152 \%$ in female, respectively. The study concludes that $\mathrm{Cd}$ dietary consumption is very low, for males and for females in the different age groups. This study provides a foundation that can resolve the risk dose-dependency of $\mathrm{Cd}$ hazard.
\end{abstract}

Keywords: Risk assessment, Physiologically based pharmacokinetics model, Shellfish, Cadmium, Heavy metal.

\title{
1. Introduction
}

Because of one natural geological source, pollution by cadmium-containing fertilizers, and industrial emissions. Vegetable crops include rice, wheat, and potatoes absorb cadmium from soil. Some researchers showed that cadmium poses a toxicity threat to human health through groundwater, basil plants, or animal. (Lajayer et al., 2019). Seafood such as fish, prawns, mussels, oyster, clams are regularly an accumulation of heavy metal such as cadmium $(\mathrm{Cd})$, copper $(\mathrm{Cu})$, zinc $(\mathrm{Zn})$, lead $(\mathrm{Pb})$, arsenic (As). Cadmium is accumulated in fish, meat, liver, kidney of sheep, cow (Ahmed et al., 2015; Ruiz-Fernandez et al., 2018). These studies show that the toxic metals can enter aquatic organism via water, food and accumulate in subcellular compartments of tissues, controlling by geochemical, physiological factors such as ions, salinity (Pan, 2009). The important effect on human health is considered to be the toxic effect on the renal proximal tubules which can result in clinical kidney disease. The method for assessing cadmium and managing risk in the occupational setting is necessary. The method for assessing cadmium in food is a measurement of tubular kidney effects and of the urinary excretion of cadmium (Wang et al., 2017).

The risk assessments organization of European Food Safety Authority (EFSA) and WHO/JECFA indicated that kidney dysfunction was considered as a critical effect with the lowest exposure. An unsureness regarding low dose kidney effects and the increasing number of proofs for low-dose bone effects make necessarily the organization of risk assessment to consider bone effects so as to appear to be a possible critical effect (European Food Safety, 2009). A lot of the previous studies published risk assessments for human health as the critical evidence of the effects of cadmium on 
kidneys. The Physiologically-based pharmacokinetics (PBPK) often estimates risk to human health or it can be used as a tool for drug (Charnick et al., 1995). PBPK model should is to evaluate the human exposure and health risk modeling framework that object to address chemical contaminants (Sasso et al., 2010). Hence, the primary focus of this study is on the risk assessment of low-level exposures to cadmium through the consumption of shellfish in Taiwan in order to provide a piece of information for preventive action to protect human health. This study designs the PBPK model to estimate the organ-specific cadmium levels in the non-smoking group with a quantitative risk assessment for human health exposed to cadmium.

The remainder of this paper is organized as follows. Section 2 describes the literature review. Section 3 describes the proposed human PBPK model to evaluate Cadmium exposure through shellfish consumption in Taiwan. Section 4 describes the evaluations. Finally, section 5 gives the concluding remarks.

\section{Literature Review}

In essence, physiologically based pharmacokinetic modeling (PBPK) models describe the physiological, biochemical, and physicochemical determinants through absorption, distribution, metabolism, and excretion (ADME) of chemicals in the body human or animal. The models are generally combined with three main parts: speciesspecific physiological parameters, chemical-specific parameters, and the structural model. The parameters of physiological comprise body weight, cardiac output, mass and volume of the organ, blood flow, vascular space of each organ, tissue composition, and metabolizing enzyme phenotype (Lin et al., 2016). Chemical-specific parameters include constituting partition and permeability coefficients, metabolic rate constants, protein binding affinity, and enzyme or transporter activity. Some formed studies estimate as a linear bioaccumulation factor with a greater risk for human health. Other linear such as bio-concentration factors estimate the transition of cadmium from the population environment such as air, cigarettes, food, drink water, soil exposure to human organs. Prediction of daily intake of cadmium considers Cd-bioavailability through consumption of rice pollution without statistical the uncertainty of the model (Zhao et al., 2017). The research of the French Nutrition and Health Survey (ENNS), based on dietary intake using the PBPK model biomonitoring data to assess the risk of cadmium exposure from external and internal critical values relative to the effect of a kidney, urinary through smoking habits and contamination level in food, cigarette combined with Bayesian population model (Bechaux et al., 2014). The PBPK model is also to assess human health risk to cadmium through inhalation and seafood consumption assessed human renal dysfunction and peripheral arterial disease risks for a long-term cadmium exposure (Ju et al., 2012). For human ingestion of fish had higher bio-accessibility than shellfish. Results indicated that the differences between gender and smoker by the damage of glomerular, tubular and smokers had higher morbidity risk of peripheral arterial disease than those of nonsmoker with ingestion seafood of cadmium exposure. The link among urinary cadmium and dietary intake to determine the risk assessment of long-term cadmium exposure, the model is modified from the original version of the K\&N conjunct to modify the one-compartment model (Amzal et al., 2009; Nordberg et al., 2018). The PBPK model is applied to determine the urinary cadmium excretion in humans through the measurements of soil-rice (Liu et al., 2018). Some research modified the version of the K\&N to reconsider the most sensitive parameters in organs such as blood, plasma, kidney, cortex, urinary excretion. These references implemented the PBPK to determine the effect of exposure to heavy metal on human health, but they did not mention the whole process to control that heavy 
metals.

In this study, it is to design a human PBPK model to evaluate Cadmium exposure through shellfish consumption in Taiwan. The evaluation model is modified from the K\&N model and PBPK model. The K\&N model of Nordberg \& Kjellstrom is applied due to a most important model and as well as the basis for other published cadmium PBPK models (Nordberg \& Kjellstrom, 1979). The K\&N model has been applied to simulated cadmium exposed through consumption of food into the body of a human (Fransson et al., 2014; Ju et al., 2012). It clearly provides evidence to predict urinary the concentration of cadmium through oral injection which based on the data from the national health and nutrition examination survey (NHANES) (Ruiz et al., 2010).

\section{The Human Physiologically Based Pharmacokinetic Model}

The human Physiologically based pharmacokinetic (PBPK) model uses to evaluate Cadmium exposure through shellfish consumption, which is composed the absorption, transport, and distribution, excretion, accumulation of cadmium flowing three blood compartments to other tissue. It establishes the average daily intake of cadmium through the consumption of shellfish in Taiwan. The model investigates the dose-response analysis of peripheral arterial disease prevalence and glomerular and tubular damage. It calculates the exceedance risk, data analysis. Figure 1 is the proposed PBPK model for cadmium exposure. The model describes the absorption of cadmium from intestine to tissue compartments including other tissue, kidney, liver connect with blood flow, and excretion by urine and fecal. The detail evaluation processes are described as follows.

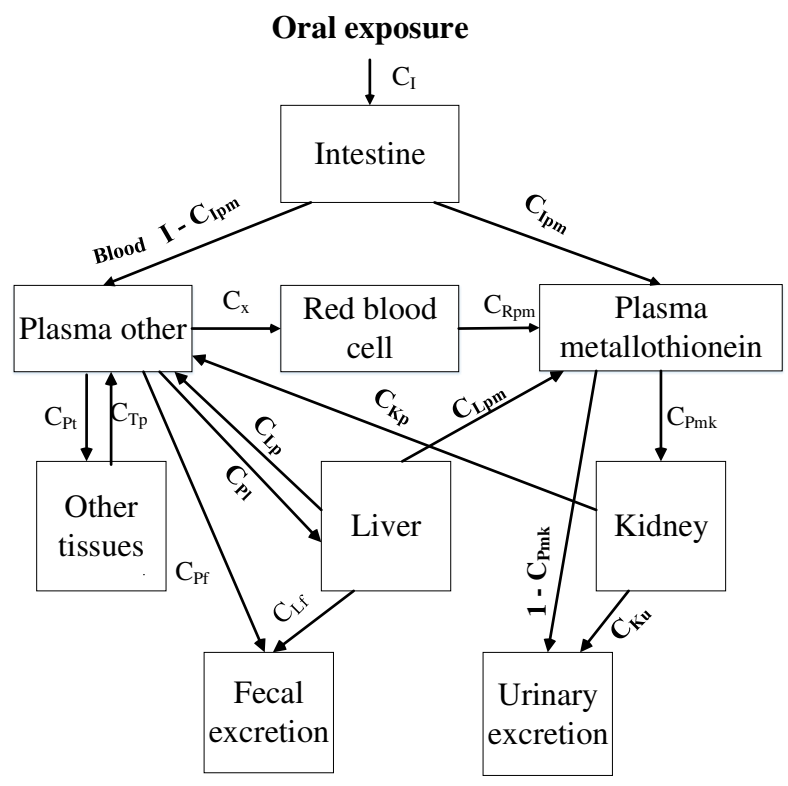

Figure 1. The PBPK model for cadmium exposure through shellfish consumption.

(1) The use of differential equations to describe transfers of cadmium consumption of shellfish which called: oral exposure to amount and flow between 7 compartments: intestine (I), 3 blood compartment including plasma other (PL), red blood cell (R), plasma metallothionein (PM), liver (L), kidney $(\mathrm{K})$, other tissue (OT) and two excretion routes: feces $(\mathrm{F})$ and urine $(\mathrm{U})$ and some adaption with the algorithms for males and females to be consistent with organ weights to calculate age-specific cadmium concentrations from tissue cadmium burdens.

(2) This model eliminated the model lung compartment when compared with the 
original model of Kjellstrom-Nordberg because of other pathways for instance inhalation or dermal contact which is mentioned to be not important than intestine absorption (Ji et al., 2013).

(3) The main purpose of this study is to focus on the nonsmokers and estimate the health risk through the consumption of shellfish which is the product hidden cadmium. Table 1 presents the prior ranges of parameter values and final values (Fransson et al., 2014; Nordberg \& Kjellström, 1979).

Table 1. Model parameters with initial ranges and final estimates

\begin{tabular}{ccccc}
\hline \multirow{2}{*}{ Coefficient } & \multirow{2}{*}{ Unit } & \multicolumn{3}{c}{ Initially assumed range } \\
\cline { 3 - 5 } & - & 0.03 & Maximum & Final estimate \\
\hline $\mathrm{C}_{\mathrm{I}}$ & - & 0.2 & 0.1 & 0.048 \\
$\mathrm{C}_{\mathrm{Ipm}}$ & - & 0.4 & 0.4 & 0.25 \\
$\mathrm{C}_{\mathrm{Pt}}$ & - & 0.05 & 0.44 \\
$\mathrm{C}_{\mathrm{Pf}}$ & - & 0.1 & 0.4 & 0.27 \\
$\mathrm{C}_{\mathrm{Pl}}$ & - & 0.0 & 0.0001 & 0.25 \\
$\mathrm{C}_{\mathrm{Lp}}$ & day $^{-1}$ & 0.0002 & 0.00003 \\
$\mathrm{CT}_{\mathrm{p}}$ & day $^{-1}$ & 0.00004 & 0.0001 & 0.00014 \\
$\mathrm{C}_{\mathrm{Kp}}$ & day $^{-1}$ & 0.0 & 0.05 & 0.00001 \\
$\mathrm{C}_{\mathrm{X}}$ & - & 0.01 & 0.015 & 0.04 \\
$\mathrm{C}_{\mathrm{Rpm}}$ & day $^{-1}$ & 0.004 & 0.0003 & 0.012 \\
$\mathrm{C}_{\mathrm{Lpm}}$ & day $^{-1}$ & 0.0001 & 0.0001 & 0.00016 \\
$\mathrm{C}_{\mathrm{Lf}}$ & day $^{-1}$ & 0.0 & 0.98 & 0.00005 \\
$\mathrm{C}_{\mathrm{Pmk}}$ & - & 0.8 & 0.0002 & 0.95 \\
$\mathrm{C}_{\mathrm{ku}}$ & day $^{-1}$ & 0.00002 & 0.5 & 0.00014 \\
$\mathrm{C}_{20}$ & - & 0.005 & & 0.1 \\
\hline
\end{tabular}

\subsection{Absorption}

The cadmium intake through consumption of shellfish is retained in intestinal walls $3 \%$ to $10 \%(C I=0.03-0.1)$ of daily intake and retained in the intestinal. The total daily absorbed amount in intestinal (I) is calculated as $I=d^{*} C_{I}, I_{I}=I-I_{2}$ and $I_{2}=C_{I} p m * I$. Where $I$ is the daily absorbed amount of cadmium in intestinal $\left(\mu \mathrm{g} \mathrm{day}^{-1}\right), I_{l}$ is the daily absorbed amount from intestine to plasma other $\left(\mu \mathrm{g} \mathrm{day}^{-1}\right), I_{2}$ is the daily absorbed amount from intestine to metallothionein $\left(\mu \mathrm{g}\right.$ day $\left.^{-1}\right), d$ is average daily intake of cadmium $\left(\mu \mathrm{g} \mathrm{kg}^{-1}\right.$ day $\left.^{-1}\right), C_{I}$ is the assumption of retention in the intestinal (\%), $C_{I p m}$ is the accumulation of cadmium in the kidney which is received a certain fraction (\%). (Nordberg \& Kjellström, 1979).

\subsection{Distribution}

A probable proportion of plasma cadmium will be blended into metallothionein. In this case, cadmium will quickly transfer to the kidney. Two forms of metallothionein will occur, one compound regard their relative accumulation, and the other compound is urinary excretion. Cadmium in the blood is mostly initiated in the plasma immediately after injection into experimental animals (Nordberg \& Kjellström, 1979). During the initial 24 hours, there is an express diffusion from plasma and establish in the blood cells, and then at repeated injections, a bigger proportion of blood cadmium is recognized in the blood cells. Cadmium in blood cells is almost bound to a similar size protein as metallothionein. It is not promptly convertible into plasma cadmium. Blood-cell cadmium will probably be removed slowly as the blood cells take over and it will be moved to the kidney (Nordberg \& Kjellström, 1979).

The binding of cadmium in the various tissue is much stronger than the plasma other. Thus, the proportion of transferring from plasma other (PL) to the tissues will be higher than the transfer back from the tissues. This indicating that $C_{P t}$ is much larger 
than $C_{T P}$, and $C_{P l}$ is much larger than $C_{L p}$. The initial value of the proportion concentration of cadmium from plasma other (PL) to other tissues (OT) and liver (L) is assumed to be proximate to their distribution of body burden in the order of $50 \%$ in $(\mathrm{OT})$ and $16 \%$ in (L). Consequently, the value of $C_{P t}$ and $C_{P l}$ are calculated at 0.4 to 0.8 and 0.1 to 0.4 , respectively.

\subsection{Accumulation}

A numerous accumulation of cadmium occurs in the compartments liver (L), kidney $(\mathrm{K})$, and other tissue (OT). A certain part of the liver cadmium will be released to plasma metallothionein $\left(\mathrm{C}_{\mathrm{Lpm}} \times \mathrm{L}\right)$. The main accumulation reaches in the compartments liver (L), kidney $(\mathrm{K})$, and other tissue (OT). According to previous research from a one-compartment metabolic model, the half-time of cadmium in the liver approximately estimates to be about 7 years. This study initially presumes $\mathrm{C}_{\mathrm{Lp}}=$ 0 to $0.0001\left(\right.$ day $\left.^{-1}\right)$ and $C_{L p m}=0.0001$ to $0.0003\left(\right.$ day $\left.^{-1}\right)$ together with $C_{L f}$ giving a halftime in the liver of 4 to 19 years. When compared to the half-life in the kidney with the liver that the half-life in the kidney is twice than in the liver approximately $0.007 \%$ of body burden is excreted daily in the urine (Nordberg et al., 2018; Nordberg \& Kjellström, 1979). Thus, the value of $\mathrm{C}_{\mathrm{Ku}}$ and $\mathrm{C}_{\mathrm{Kp}}$ in the order of 0.00005 to 0.0002 day $^{-1}$ and 0 to 0.0001 day $^{-1}$. The proportional range of half-time in the kidney will be around 6 to 38 years. The decrease of the total number of tubular cells will directly affect to decrease of reabsorption in the tubular. The reason for a loss of cells will cause an increase in the transport of cadmium from kidney tubules to blood. It also increases excretion of cadmium from tubules to urine (Nordberg \& Kjellström, 1979). $C_{d c}$ has assumed the range of 0 to 0.000002 day $^{-1}$. The initial value of $\mathrm{C}_{\mathrm{Tp}}$ is assumed 0.00004 to 0.0002 day $^{-1}$ because $50 \%$ of the total body burden will be in other tissue (OT) in the long-term with low-level exposure. The estimation of the whole-body half-life ranges from 10 to 30 years and the half-life in muscles are longer than the liver and kidney. Therefore, other tissue compartments have a relatively long half-life and suitable to the coefficients of the model that about half of the body burden would be into other tissue in older age groups ( $>40$ years).

The consistent flow of cadmium among the compartments including plasma other (PL), red blood cell (R), plasma metallothionein (Pm), whole blood (WBL), liver (L), kidney $(\mathrm{K})$, other tissues (OT) in the model can be shown by a list of differential equations. Equations are calculated as formula (1) to (7).

$$
\begin{aligned}
& P L=I_{l}+C_{T p} * O T+C_{L p} * L+K^{*} C_{K p} \\
& d / d t(R)=C_{X} * P L-C_{R p m} * R \\
& P m=I_{2}+C_{R p m} * P L+C_{L p m} * L \\
& W B L=R+C_{20} *(P L+P m) \\
& d / d t(L)=C_{P l} * P L-\left(C_{L p}+C_{L p m}+C_{L f}\right) * L \\
& d / d t(K)=C_{P m k} * P m a-\left(C_{K u}+C_{K p}\right) * K \\
& d / d t(O T)=C_{P t} * P L-C_{T p} * O T
\end{aligned}
$$

Where plasma other (PL) is the amount of cadmium reaching plasma other compartments $\left(\mu \mathrm{g} \mathrm{day}^{-1}\right)$, other tissues (OT) is a numerous accumulation of cadmium occurs in other tissues compartment $\left(\mu \mathrm{g} \mathrm{day}^{-1}\right)$, liver $(\mathrm{L})$ is a numerous accumulation of cadmium occurs in liver compartment $\left(\mu \mathrm{g}\right.$ day $\left.^{-1}\right), C_{T p}$ is fraction from plasma other to other tissues (-), $C_{L p}$ is transfer rate from liver to plasma other $\left(\right.$ day $\left.^{-1}\right)$, kidney $(\mathrm{K})$ is a numerous accumulation of cadmium occurs in kidney compartment $\left(\mu \mathrm{g} \mathrm{day}^{-1}\right), C_{K p}$ is transfer rate from kidney to plasma other $\left(\right.$ day $\left.^{-1}\right),(\mathrm{R})$ is a numerous accumulation of cadmium occurs in red blood cell $(\mathrm{R})\left(\mu \mathrm{g}\right.$ day $\left.^{-1}\right), C_{X}$ is Fraction from plasma other to red blood cells (-), $C_{R p m}$ is transfer rate from red blood cells to plasma metallothionein $\left(\right.$ day $\left.^{-1}\right)$, plasma metallothionein $(\mathrm{Pm})$ is the amount of cadmium reaching plasma 
metallothionein $\left(\mu \mathrm{g} \mathrm{day}^{-1}\right), C_{L p m}$ is transfer rate from liver to plasma metallothionein Fraction of PL and Pm in total blood $\left(\mathrm{day}^{-1}\right)$, whole blood (WBL) is a numerous accumulation of cadmium occurs total which calculate from plasma other, red blood cell, and plasma metallothionein $\left(\mu \mathrm{g} \mathrm{day}^{-1}\right), C_{20}$ is fraction of cadmium in the plasma compartments contributing to whole blood (-), $\mathrm{C}_{\mathrm{Pl}}$ is fraction from plasma other to liver $\left(\right.$ day $\left.^{-1}\right), C_{L f}$ is excretion rate from liver to feces $\left(\right.$ day $\left.^{-1}\right), C_{P m k}$ is tubular reabsorption capacity (-), $C_{K u}$ is excretion rate of cadmium accumulated in kidney to 24-h urine (-), $C_{K p}$ is transfer rate from kidney to plasma other $\left(\right.$ day $\left.^{-1}\right), C_{P t}$ is fraction from plasma other to other tissues (-) (Fransson et al., 2014; Nordberg \& Kjellström, 1979).

\subsection{Excretion}

A large proportion of cadmium excreted through feces and urine and the proportion excretion of cadmium is depended on body burden. However, the excretion rate is depended on a function of the dose. The limit of the daily dose is $\left(0.25 \mathrm{mg} \mathrm{kg}^{-1}\right.$ body weight in mice), the rate of urinary excretion is around $0.01 \%$ of body burden and in human being is assumed about $0.007 \%$ (Nordberg \& Kjellström, 1979). The certain proportion $\left(\mathrm{C}_{\mathrm{Pf}}\right)$ of cadmium in blood (PL) that predicted excretion through the intestinal wall to the feces $\left(\mathrm{C}_{\mathrm{Pf}} \times \mathrm{P}\right)$ and the range of 0.005 to 0.5 . A proportion $\left(\mathrm{C}_{\mathrm{Lf}}\right)$ of cadmium in the liver is assumed to be excreted via bile to the feces $\left(\mathrm{C}_{\mathrm{Lf}} \times \mathrm{L}\right)$. Only a small proportion $(0.1-0.4 \%)$ of the injected dose is excreted for 24 hours. Consequently, the proportion of $\mathrm{C}_{\mathrm{Lf}}$ is assumed in the range of 0 to 0.0001 day $^{-1}$. The total daily excreted amount of cadmium at a steady-state would be similar to the daily absorbed amount (Nordberg \& Kjellström, 1979). For example, the average daily intake of an adult in food is $16 \mu \mathrm{g}$ and the absorption rate would be 5\%, the average body burden is $5 \mathrm{mg}$, then the daily absorption amount is assumed $0.016 \%$ of body burden. The excretion of urinary is $0.007 \%$ and the fecal excretion would be $0.009 \%$. The main purpose of modeling is assumed the fecal excretion of body burden and urine excretion value around 0.002 to $0.02 \%$ (Nordberg \& Kjellström, 1979).

In order to calculation the amount excretion of cadmium through feces and urine is calculated as formula (8) and (9).

$$
\begin{aligned}
& U=P m a^{*}\left(1-C_{P m k}\right)+C_{K u} * K \\
& F=C_{P f} * P L+C_{L f}{ }^{*} L
\end{aligned}
$$

Where urine $(\mathrm{U})$ is the proportion excretion of cadmium in urine $\left(\mu \mathrm{g} \mathrm{day}^{-1}\right)$, feces (F) is the proportion excretion of cadmium in feces $\left(\mu \mathrm{g}\right.$ day $\left.^{-1}\right), C_{P f}$ is fraction from plasma other to fecal excretion (-), $C_{L f}$ is excretion rate from liver to feces $\left(\right.$ day $\left.^{-1}\right)$.

\subsection{Data collection}

Average daily intake of cadmium (d) $\left(\mu \mathrm{g} \mathrm{kg}^{-1} \mathrm{day}^{-1}\right)$ from shellfish consumption are calculated shellfish ingestion rate (IR) $\left(\mathrm{g}^{-1 a y^{-1}}\right)$ multiplying by the cadmium concentration (C) ( $\mu \mathrm{g} \mathrm{g}^{-1}$ wet $\left.\mathrm{wt}\right)$ in shellfish and then divided by the body weight of the individual (kg) (BW) (Diamond et al., 2003). In brief, the average intake of cadmium (d) is calculated as the formula (10).

$$
d=\frac{(C * I R)}{B W}
$$

The cadmium concentration (C) is estimated to be $0.62 \pm 49.73$ ( $\mu \mathrm{gg}-1$ wet wt) of cadmium on shellfish as show in Table 2 (Ju et al., 2020; Ju et al., 2012; Lin et al., 2004; Wang \& Lu, 2017). Table 3 presents the following assumption including the shellfish ingestion rate (IR) with the body weight follows by National Food Consumption Database in Taiwan.

\subsection{Dose-response analysis}

This study reanalyzes the published data and renovate two dose-response relationship (Tellez-Plaza et al., 2010). The level of cadmium in urine $\left(\mathrm{Cd}_{\mathrm{U}}\right)$ and glomerular and 
Table 2. Cadmium content of shellfish in Taiwan

\begin{tabular}{|c|c|}
\hline Species & Cd concentration ( $\mu \mathrm{g} \mathrm{g}^{-1}$ wet $\left.\mathrm{wt}\right)$ \\
\hline Oyster Crassostrea gigas ${ }^{a}$ & $\mathrm{LN}(0.25,1.84)^{\mathrm{e}}$ \\
\hline Hard clam Meretrix lusoria ${ }^{a}$ & $\mathrm{LN}(0.12,2.31)$ \\
\hline Freshwater clam Corbicula fluminea ${ }^{a}$ & $\mathrm{LN}(0.16,1.35)$ \\
\hline Other shellfish ${ }^{\mathrm{a}}$ & $\mathrm{LN}(0.11,0.18)$ \\
\hline \multirow[t]{2}{*}{ Hard clams Meretrix lusoria ${ }^{b}$} & $0.2 \pm 0.08^{\mathrm{f}}$ \\
\hline & $(0.05-0.38)^{\mathrm{g}}$ \\
\hline \multirow{2}{*}{ Oyster Crassostrea gigas $(\mathrm{n}=59)^{\mathrm{d}, \mathrm{k}}$} & $0.16 \pm 0.31$ \\
\hline & $(0.02-2.44)$ \\
\hline \multirow{2}{*}{$\begin{array}{l}\text { Clams Meretrix lusoria }(\mathrm{n}=14)^{\mathrm{k}} \\
\text { Venus clams Ruditapes variegate }(\mathrm{n}=10)\end{array}$} & 0.19 \\
\hline & $(0.02-0.79)$ \\
\hline Mussels Perna viridis & 0.03 \\
\hline Mussels Sanguinolaria diphos (Linnaeus) ${ }^{\mathrm{c}}$ & 0.02 \\
\hline \multirow[t]{2}{*}{ Clams Katelysia hiantina ${ }^{\mathrm{c}}$} & 0.06 \\
\hline & $(0.01-0.11)$ \\
\hline \multirow{2}{*}{ Clams Anomalocardia squamosac } & 0.06 \\
\hline & $(0.02-0.12)$ \\
\hline \multirow{2}{*}{ Clams Anadara antiquata ${ }^{\mathrm{c}}$} & 0.29 \\
\hline & $(0.07-0.79)$ \\
\hline \multirow[t]{2}{*}{ Clams Phyllotreta undulata ${ }^{c}$} & 0.07 \\
\hline & $(0.009-0.17)$ \\
\hline Total concentration of cadmium & $\mathrm{N}(0.62 \pm 49.73)$ \\
\hline
\end{tabular}

$\overline{\mathrm{a}, \mathrm{b}}$ Adopted from (Ju et al., 2012). ${ }^{\mathrm{c}}$ Adopted from (Wang \& Lu, 2017). ${ }^{\mathrm{d}}$ Adopted from (Lin et al., 2004). ${ }^{\mathrm{e}} \mathrm{LN}(\mathrm{a}, \mathrm{b})$ : lognormal distribution with geometric mean $a$ and geometric standard deviation $b .{ }^{\mathrm{f}}$ Mean \pm standard deviation. ${ }^{\mathrm{g}}$ Range. ${ }^{\mathrm{k}}$ Number of samples.

Table 3. The amount of shellfish consumed in Taiwan

\begin{tabular}{lccccccc}
\hline \multirow{2}{*}{ Age } & Average & \multicolumn{7}{c}{ Shellfish cooked weight $\left(\mathrm{g} \mathrm{day}{ }^{-1}\right)$} \\
\cline { 2 - 8 } & Weight $(\mathrm{BW})$ & Min & Max & Mean & SE & SD & P95 \\
\hline 0-3 Male & 12.70 & 0.00 & 74.42 & 1.29 & 0.36 & 6.54 & 6.77 \\
0-3 Female & 12.09 & 0.00 & 33.19 & 0.91 & 0.23 & 4.17 & 5.11 \\
3-6 Male & 19.97 & 0.00 & 129.16 & 1.84 & 0.46 & 9.94 & 6.65 \\
3-6 Female & 19.44 & 0.00 & 74.48 & 1.21 & 0.28 & 6.03 & 7.24 \\
6-12 Male & 37.10 & 0.00 & 131.63 & 2.14 & 0.38 & 11.51 & 7.50 \\
6-12 Female & 35.19 & 0.00 & 186.32 & 2.02 & 0.33 & 10.01 & 12.61 \\
12-16 Male & 57.95 & 0.00 & 83.35 & 1.83 & 0.34 & 8.53 & 11.49 \\
12-16 Female & 52.11 & 0.00 & 161.18 & 1.52 & 0.36 & 8.77 & 9.26 \\
16-18 Male & 64.65 & 0.00 & 198.30 & 3.60 & 1.14 & 18.12 & 14.20 \\
16-18 Female & 55.79 & 0.00 & 41.62 & 1.43 & 0.41 & 6.38 & 7.13 \\
19-65 Male & 70.93 & 0.00 & 268.66 & 3.02 & 0.33 & 14.82 & 16.41 \\
19-65 Female & 58.54 & 0.00 & 132.77 & 2.10 & 0.22 & 9.76 & 13.77 \\
\hline
\end{tabular}

tubular damage (GTD) for adults and the level of cadmium in the blood $\left(\mathrm{Cd}_{\mathrm{B}}\right)$ and PADP for males and females is depicted by a 4-parameter Hill model. It is calculated as the formula (11).

$$
R\left(C d_{U, B}\right)=R_{\min }+\frac{R_{\max }-R_{\min }}{1+\left(\frac{C d_{U, B}}{E C 50}\right)^{n}}
$$

Where $C d_{U, B}$ is cadmium in urine ( $\mu \mathrm{g} \mathrm{g}^{-1}$ creatinine) and cadmium in blood ( $\mu \mathrm{g} \mathrm{\textrm {L } ^ { - }}$ $\left.{ }^{1}\right), \mathrm{R}\left(\mathrm{Cd}_{\mathrm{U}, \mathrm{B}}\right)$ is the $\mathrm{Cd}$-dependent response measured as GTD (\%) or PADP (\%), $\mathrm{R}_{\min , \max }$ are the minimum and maximum responses (\%), respectively, EC50 is the effective concentration at $50 \%$ response, and $\mathrm{n}$ is the Hill coefficient (Ju et al., 2012). 


\subsection{Exceedance risk}

The dose-response profiles are applied to the conditional probabilities. Thence, the relationship between cadmium in urine and GTD can be shown as $\mathrm{P}(\mathrm{GTD} / \mathrm{Cd})(\mathrm{Ju}$ et al., 2012). For whole blood, the relationship between cadmium in blood and PADP can be shown as $\mathrm{P}\left(\mathrm{PADP} / \mathrm{Cd}_{\mathrm{B}}\right)$. Cadmium in urine and blood can be estimated by the PBPK model through the consumption of daily shellfish. The risk of human health ( $\mathrm{R}_{\mathrm{GTD}}$, PADP) can be computed as the probability density functions of $C d_{U}$ and $C d_{B}$ multiplied by the conditions' probabilities of GTD and PADP, respectively, as formula (12) and (13).

$$
P\left(R_{G T D}\right)=P\left(C d_{U}\right) * P\left(G T D / C d_{U}\right)
$$

$$
P\left(R_{P A D P}\right)=P\left(C d_{B}\right) * P\left(P A D P / C d_{B}\right)
$$

Where $P\left(R_{G T D}\right)$ and $P\left(R_{P A D P}\right)$ express the human health risk predicts based on two responses of GTD and PADP, respectively.

\section{Evaluation}

This section describes results of modifying the dose-response profiles, estimates intake through cadmium concentration in blood, cadmium concentration in urine, probability of cadmium in blood and probability of cadmium in urine. Exceedance risk curves express the valuation probabilistic of glomerular and tubular damage and peripheral arterial disease prevalence difference population groups as show in Table 4. Results show that the GTD value can be obtained for different genders ranging from $17.8067 \%-17.8072 \%$. The value of PADP ranges from $3.2505 \%-4.5968 \%$ in males and ranges from $4.7168 \%-7.0152 \%$ in females. The detail results are shown in Figure 2.

\begin{tabular}{|c|c|c|c|c|}
\hline \multirow{2}{*}{ Age Gender } & \multicolumn{2}{|c|}{ Male } & \multicolumn{2}{|c|}{ Female } \\
\hline & GTD & PADP & GTD & PADP \\
\hline $0-3$ ages & $17.8065-17.8071$ & $3.25-4.60$ & $17.8065-17.8066$ & $4.72-6.08$ \\
\hline $3-6$ ages & $17.8066-17.8071$ & $3.25-3.49$ & $17.8068-17.8071$ & $5.27-6.40$ \\
\hline $6-12$ ages & $17.8068-17.8071$ & $3.25-3.28$ & $17.8068-17.8071$ & $6.03-6.67$ \\
\hline $12-16$ ages & $17.8070-17.8071$ & $3.28-3.29$ & $17.8070-17.8071$ & $6.67-6.92$ \\
\hline 16-18 ages & $17.8070-17.8071$ & $3.27-3.29$ & $17.8070-17.8071$ & $6.73-7.02$ \\
\hline $19-65$ ages & $17.8068-17.8071$ & $3.27-3.29$ & $17.8068-17.80-1$ & $6.57-6.81$ \\
\hline
\end{tabular}

Table 4 Human health risk of GTD (\%) and PADP $(\%)$ of intake Cd from Shellfish.
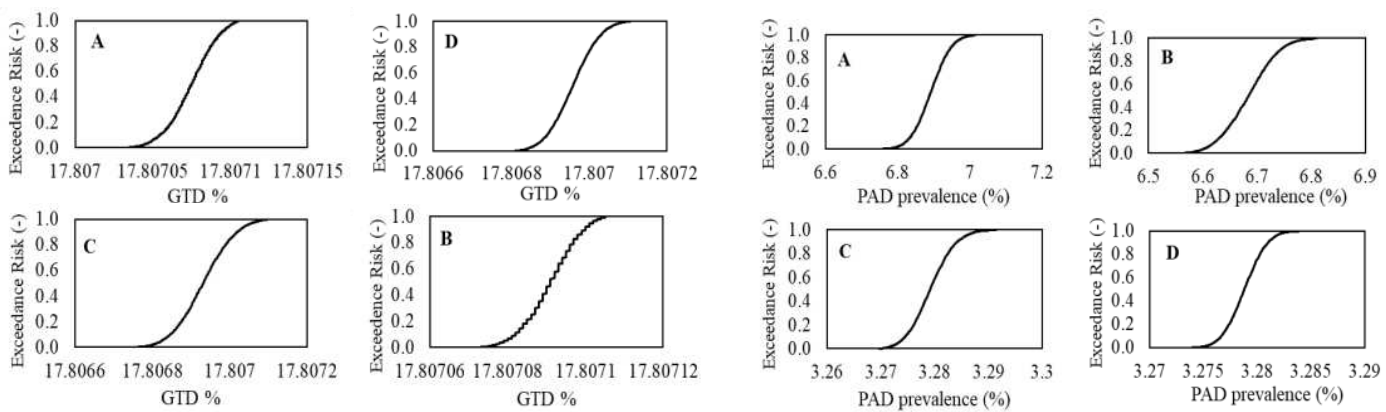

Figure 2. (A) exceedance risk of GTD and PADP group 16-18 ages for male, (B) exceedance risk of GTD and PADP group 16-18 ages for female, (C) exceedance risk of GTD and PADP group 19-65 ages for male, (D) exceedance risk of GTD and PADP group 19-65 ages for female.

One of the main implementations of the PBPK model is the process of linking long-term exposure measurements of a chemical. For that reason, this research 
discusses the individual linkage among consumption of shellfish, urine, and blood cadmium concentrations and the consideration of the population variations. This study anticipates the average valuation of urinary and blood cadmium and total cadmium intake within the Taiwan population including children, adults, males, and females. Furthermore, this study applies gender-specific creatinine content to modify the result of the PBPK model to decrease the urine dilution effect. People who are intake a higher absorption capacity of cadmium in the gastrointestinal tract also relates to high-risk populations for cadmium exposure. Moreover, the strengths of this study applied in the different age groups to predict cadmium concentration in urine and blood to present the individual-specific absorption abilities.

\section{Conclusion}

Due to the effecting of toxic cadmium on human health such as on kidneys, bones, cancer when human have a long-term exposure of cadmium. Then, the present study proposed a model to assess the effect of exposure cadmium on the human body. This study designs physiologically based pharmacokinetic modeling to assess low-level cadmium exposure from the diet. In order to assess human renal dysfunction and peripheral arterial disease risks for long-term cadmium exposure, this study is used the Hill-based dose-response model. The predictive ability of the model, this study is evaluated using the Monte Carlo simulations. Gender differences in the association with the absorption of cadmium on the human body are evaluated using data from children $0-3$ age to adults $\leq 65$ age. Depending on the gender corresponding with the level of renal effect. Glomerular and tubular damage (GTD) is different between group ages and genders ranged from $17.8067 \%-17.8072 \%$, respectively. The peripheral arterial disease prevalence (PADP) is ranging from $3.2505 \%-4.5968 \%$ in males and ranging from $4.7168 \%-7.0152 \%$ in females, respectively.

Results of this research proposed that cadmium dietary exposure via shellfish consumption is very low, for males and for females in the different age groups. Results indicated that there is no significant risk present by cadmium. However, this study suggests that a probable health risk will be appeared by long-term exposure to low-level cadmium among the general populations through the consumption of shellfish.

\section{Acknowledgment}

The Ministry of Science and Technology of the R.O.C. under the grant MOST 1082221-E-019-046-MY2 and MOST 109-2221-E-019-033 support this research.

\section{Funding}

The Ministry of Science and Technology of the R.O.C. under the grant MOST 1082221-E-019-046-MY2 and MOST 109-2221-E-019-033 support this research.

\section{Availability of data and materials}

(1) The datasets generated from an open access database are available in the 'National Food Consumption Database' repository, http://tnfcds.cmu.edu.tw/index.php?action $=$ download\&p $=6$

(2) The datasets are analyzed by the proposed method of this study.

\section{Declarations \\ Ethics approval and consent to participate \\ Not applicable.}

\section{Consent for publication}


Not applicable.

\section{Competing interests}

The authors declare that they have no competing interests.

\section{Reference}

Ahmed, M. K., Baki, M. A., Islam, M. S., Kundu, G. K., Habibullah-Al-Mamun, M., Sarkar, S. K., \& Hossain, M. M. (2015). Human health risk assessment of heavy metals in tropical fish and shellfish collected from the river Buriganga, Bangladesh. Environmental Science and Pollution Research, 22(20), 15880-15890.

Bechaux, C., Bodin, L., Clemencon, S., \& Crepet, A. (2014). PBPK and population modelling to interpret urine cadmium concentrations of the French population. Toxicology and Applied Pharmacology, 279(3), 364-372.

Charnick, S. B., Kawai, R., Nedelman, J. R., Lemaire, M., Niederberger, W., Sato, H. J. J. o. p., \& biopharmaceutics. (1995). Physiologically based pharmacokinetic modeling as a tool for drug development. Journal of Pharmacokinetics and Biopharmaceutics, 23(2), 217-229.

Diamond, G. L., Thayer, W. C., Choudhury, H. J. J. o., \& Environmental Health, P. A. (2003). Pharmacokinetics/pharmacodynamics (PK/PD) modeling of risks of kidney toxicity from exposure to cadmium: estimates of dietary risks in the US population. Journal of Toxicology and Environmental Health, 66(22), 2141-2164.

EFSA (European Food Safety Authority). (2009). European Food Safety Authority. EFSA J, 980, 981.

Fransson, M. N., Barregard, L., Sallsten, G., Akerstrom, M., \& Johanson, G. (2014). Physiologically-Based Toxicokinetic Model for Cadmium Using Markov-Chain Monte Carlo Analysis of Concentrations in Blood, Urine, and Kidney Cortex from Living Kidney Donors. Toxicological Sciences, 141(2), 365-376.

Ji, K., Kim, J., Lee, M., Park, S., Kwon, H. J., Cheong, H. K., Jang, J. Y., Kim, D. S., Yu, S., Kim, Y. W., Lee, K. Y., Yang, S. O., Jhung, I. J., Yang, W. H., Paek, D. H., Hong, Y. C., \& Choi, K. (2013). Assessment of exposure to heavy metals and health risks among residents near abandoned metal mines in Goseong, Korea. Environmental Pollution, 178, 322-328.

Ju, Y. R., Chen, C. F., Chuang, X. Y., Lim, Y. C., Chen, C. W., \& Dong, C. D. (2020). Biometry-dependent metal bioaccumulation in aquaculture shellfishes in southwest Taiwan and consumption risk. Chemosphere, 253, 126685.

Ju, Y. R., Chen, W. Y., \& Liao, C. M. (2012). Assessing human exposure risk to cadmium through inhalation and seafood consumption. Journal of Hazardous Materials, 227-228, 353-361.

Lajayer, B. A., Najafi, N., Moghiseh, E., Mosaferi, M., \& Hadian, J. (2019). Micronutrient and heavy metal concentrations in basil plant cultivated on irradiated and non-irradiated sewage sludge-treated soil and evaluation of human health risk. Regulatory Toxicology and Pharmacology, 104, 141-150.

Lin, H. T., Wong, S. S., \& Li, G. C. (2004). Heavy metal content of rice and shellfish in Taiwan. Food and Drug Analysis, 12(2), 167-174.

Lin, Z., Gehring, R., Mochel, J. P., Lavé, T., \& Riviere, J. E. (2016). Mathematical modeling and simulation in animal health - Part II: principles, methods, applications, and value of physiologically based pharmacokinetic modeling in veterinary medicine and food safety assessment. Journal of Veterinary Pharmacology and Therapeutics, 39(5), 421-438.

Liu, X., Zhong, L., Meng, J., Wang, F., Zhang, J., Zhi, Y., Zeng, L., Tang, X., \& Xu, J. (2018). A multi-medium chain modeling approach to estimate the cumulative 
effects of cadmium pollution on human health. Environmental Pollution, 239, 308-317.

Nordberg, G. F., Bernard, A., Diamond, G. L., Duffus, J. H., Illing, P., Nordberg, M., Bergdahl, I. A., Jin, T., \& Skerfving, S. (2018). Risk assessment of effects of cadmium on human health. Pure and Applied Chemistry, 90(4), 755-808.

Nordberg, G. F., \& Kjellström. (1979). Metabolic model for cadmium in man. Environmental Health Perspectives, 28, 211-217.

Pan, K. (2009). The subcellular fate of cadmium and zinc in the scallop Chlamys nobilis during waterborne and dietary metal exposure. Aquatic Toxicology (Amsterdam, Netherlands), 90, 253-260.

Ruiz, P., Fowler, B., Osterloh, J., Fisher, J., Mumtaz, M. J. S., \& Research, Q. i. E. (2010). Physiologically based pharmacokinetic (PBPK) tool kit for environmental pollutants-metals. SAR and QSAR in Environmental Research, 21(7-8), 603-618.

Sasso, A. F., Isukapalli, S. S., \& Georgopoulos, P. G. (2010). A generalized physiologically-based toxicokinetic modeling system for chemical mixtures containing metals. Theor Biol Med Model, 7, 17.

Tellez-Plaza, M., Navas-Acien, A., Crainiceanu, C. M., Sharrett, A. R., \& Guallar, E. (2010). Cadmium and peripheral arterial disease: gender differences in the 19992004 US National Health and Nutrition Examination Survey. Am J Epidemiol, 172(6), 671-681.

Wang, W. X., \& Lu, G. (2017). Chapter 21 - Heavy Metals in Bivalve Mollusks. In D. Schrenk \& A. Cartus (Eds.), Chemical Contaminants and Residues in Food (Second Edition), (pp. 553-594): Woodhead Publishing.

Zhao, D., Liu, R. Y., Xiang, P., Juhasz, A. L., Huang, L., Luo, J., Li, H. B., \& Ma, L. N. Q. (2017). Applying Cadmium Relative Bioavailability to Assess Dietary Intake from Rice to Predict Cadmium Urinary Excretion in Nonsmokers. Environmental Science \& Technology, 51(12), 6756-6764. 


\section{Oral exp osure}

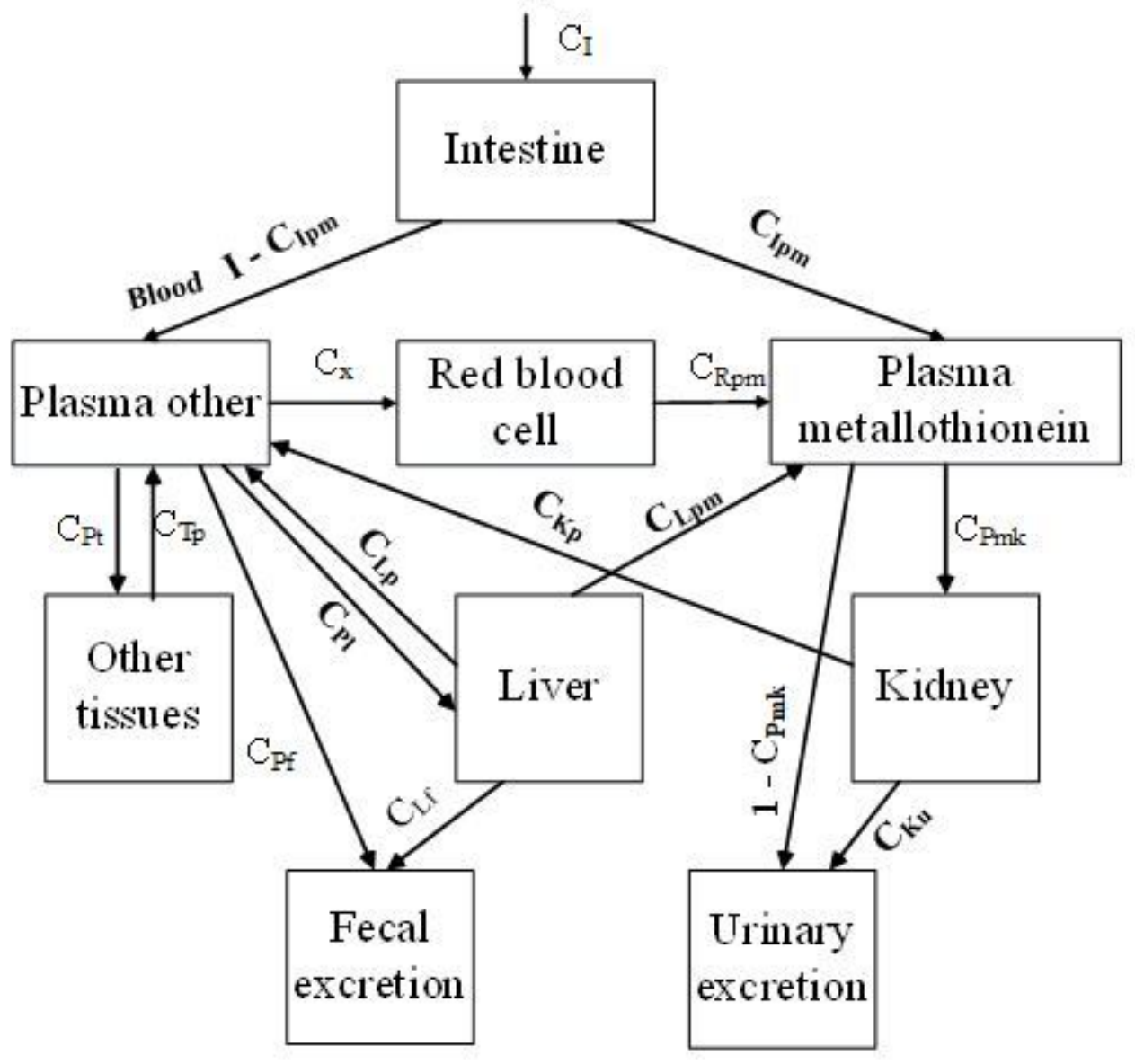

Figure 1

The PBPK model for cadmium exposure through shellfish consumption.

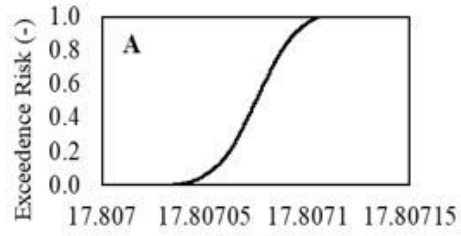

GTD \%

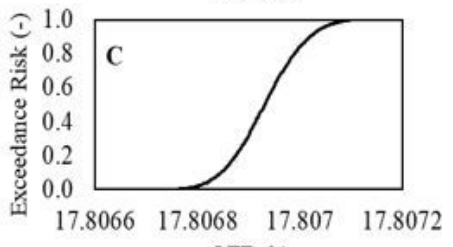

GTD \%
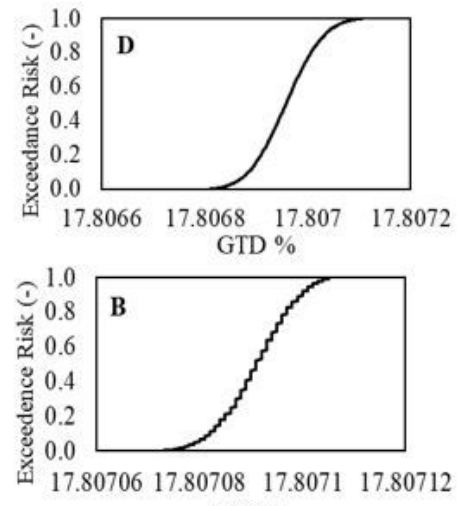

GTD $\%$
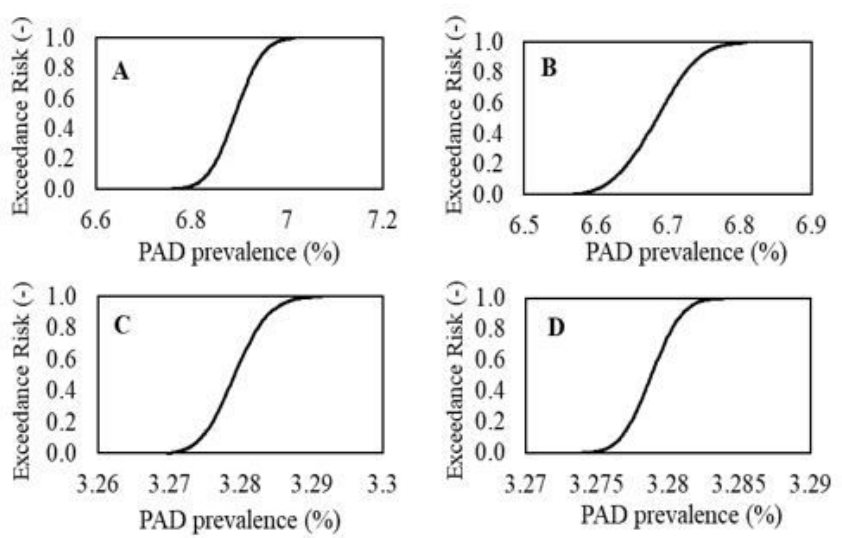

Figure 2 

(A) exceedance risk of GTD and PADP group 16-18 ages for male, (B) exceedance risk of GTD and PADP group 16-18 ages for female, (C) exceedance risk of GTD and PADP group 19-65 ages for male, (D) exceedance risk of GTD and PADP group 19-65 ages for female. 